\title{
Crescimento demoeconômico e desigualdade no século XXI
}

\author{
José Eustáquio Diniz Alves* \\ Miguel Antônio Pinho Bruno*
}

\begin{abstract}
PIKETTY, Thomas. Capital in the twenty-first century. Boston: Harvard University Press, 2014.
\end{abstract}

O livro Capital in the twenty-first century, do professor da Escola de Economia de Paris, Thomas Piketty, lançado originalmente em francês, tornou-se um best seller a partir da sua edição em inglês publicada pela Harvard University Press, no primeiro semestre de 2014. Manter-se no topo da lista dos livros mais vendidos é um fato notável para uma obra de economia com cerca de 700 páginas. Talvez o sucesso se explique pela riqueza da análise e o esforço exaustivo de pesquisa, que possibilitou a criação de uma base de dados sobre desigualdade de renda, riqueza e crescimento econômico no longo prazo.

O livro de Piketty chamou a atenção, em especial, pela forma como descreve o aumento da desigualdade de renda e da riqueza nos países. Logo na introdução, Piketty realça a questão da desigualdade ao perguntar se a acumulação de capital (crescimento da economia no longo prazo) leva à concentração do patrimônio em cada vez menos mãos, como acreditava Karl Marx, ou à redução das desigualdades e a uma maior harmonia entre as classes, como pensava Simon Kuznets. Como o próprio título do livro demonstra, o autor tende a dar razão a Marx.

Mas as contribuições do livro cobrem um espectro mais amplo. Para a demografia, esta obra é uma referência importante para a compreensão das tendências históricas do tema população e desenvolvimento e representa uma grande contribuição para a análise da dinâmica econômica, demográfica e o progresso dos padrões de vida humana, em suas diferentes escalas e dimensões.

\footnotetext{
*Escola Nacional de Ciências Estatísticas (Ence), Instituto Brasileiro de Geografia e Estatística (IBGE), Rio de Janeiro-RJ, Brasil (jose.diniz@ibge.gov.br).

*** Escola Nacional de Ciências Estatísticas (Ence), Instituto Brasileiro de Geografia e Estatística (IBGE), Rio de Janeiro-RJ, Brasil (miguel.bruno@ibge.gov.br).
} 
Piketty comenta corretamente, na Introdução do livro, que é impossível entender as previsões exageradamente sombrias de Thomas Malthus sem reconhecer o medo das elites europeias em relação aos ideais progressistas da Revolução Francesa. O progresso não fazia parte do pensamento do reverendo Malthus, pois, em seu modelo, o crescimento populacional tendia sempre a superar o crescimento econômico, inviabilizando, portanto, o desenvolvimento de longo prazo. Mas antes de Malthus, conforme destacado por Piquetty no capítulo 10, o marquês de Condorcet, matemático, iluminista e destacada liderança da Revolução Francesa, considerava que, prevalecendo o Estado de Direito e os ideais da tríade Igualdade, Liberdade e Fraternidade, poderia haver desenvolvimento econômico com maior igualdade de acesso à riqueza.

De fato, o desenvolvimento econômico é um fato novo na história da humanidade. Tendo como referência os estudos de Angus Maddison (2007), Piketty apresenta, no capítulo 2, os dados históricos do crescimento populacional e econômico. A tabela 2.1 mostra que, entre o ano 1 e o de 1700, tanto o crescimento da economia quanto o da população mundial corresponderam a mero 0,1\% ao ano, resultando em estagnação da renda per capita mundial durante os primeiros 17 séculos da era Cristã. Entre 1700 e 1820, houve aceleração do crescimento populacional (0,4\% a.a.) e econômico (0,5\% a.a.), mas o aumento da renda per capita mundial permaneceu muito baixo (0,1\% a.a.). Todavia, após a Revolução Industrial e Energética, houve grande crescimento da população e um incremento ainda maior do produto total da economia. A ampliação da renda per capita foi de 0,9\% ao ano, entre 1820 e 1913, e de 1,6\% ao ano, de1913 a2012. Nos chamados "Trinta anos gloriosos" (Trente Glorieuses), entre 1950 e 1980, o crescimento da renda per capita mundial atingiu seu valor máximo de 2,5\% ao ano.

Sem dúvida, o capitalismo, para o bem ou para o mal, foi o sistema de produção histórico que mais gerou riqueza material em todos os tempos, embora à custa do empobrecimento da natureza. Mas antes de entrar no debate sobre distribuição e desigualdade, vale a pena acompanhar as observações do autor sobre o ritmo do crescimento demoeconômico.

Apesar de ser um crítico do modelo malthusiano, Piketty não se furta a reconhecer o poder da "lei do crescimento acumulativo" (exponencial) que torna impossível um alto crescimento no longo prazo. Por exemplo, se o incremento populacional de $0,8 \%$ ao ano ocorrido entre 1700 e 2012 (com o pico de 2,1\% a.a. em 1965-70) se repetir nos próximos três séculos, a população mundial atingiria a casa de 70 bilhões de habitantes em 2300, o que, segundo 0 autor, "não é plausível e nem desejável” (p. 83). Sobre o futuro do crescimento populacional, Piketty trabalha com a abordagem da transição demográfica e as projeções da Divisão de População da ONU, que, no cenário médio, apontam para uma redução das taxas de crescimento, com a população global atingindo cerca de 11 bilhões de habitantes em 2100.

Em relação ao crescimento econômico, Piketty considera que os 200 anos de intenso ritmo da atividade econômica possibilitaram a diversificação da estrutura produtiva, abrindo espaço para o fenômeno da mobilidade social ascendente e para a redução das desigualdades sociais: "sociedades dominadas pelo capital no passado, com hierarquias em 
grande parte determinadas pela riqueza herdada (categoria que inclui tanto a sociedade rural tradicional quanto os países da Europa do século XIX), podem surgir e subsistir apenas em regimes de baixo crescimento" (p. 84). Dessa forma, o crescimento foi pré-condição para o desenvolvimento econômico e social, porque permitiu a expansão do estoque de riqueza, o que beneficiou a maior parte da população mundial, mesmo que os benefícios tenham sido apropriados de forma desigual.

Mas quais serão as tendências no século XXI? Piketty pergunta se estaríamos caminhando para o fim do crescimento por razões tecnológicas ou ecológicas, ou as duas ao mesmo tempo. Ele cita o trabalho acadêmico de Robert Gordon (2012), que trata de uma possível redução drástica do crescimento econômico em decorrência da estagnação da produtividade ${ }^{1}$ e do esgotamento dos benefícios do progresso técnico. $\mathrm{O}$ autor menciona também a questão da depleção dos recursos naturais e a necessidade de mudança da matriz energética diante da possibilidade do pico da produção de hidrocarbonetos, fator principal do aquecimento global. Infelizmente, Piketty não aprofunda esses dois temas (tecnologia e meio ambiente), que são centrais para definir o futuro do desenvolvimento econômico e do bem-estar humano e ambiental. A expressão “desenvolvimento sustentável” aparece, de forma marginal, apenas duas vezes nas 700 páginas do livro (p. 481 e 494). Não há, também, referências à ampla discussão sobre a Conferência das Nações Unidas sobre o Meio Ambiente e Desenvolvimento (Rio 1992 e Rio+20), nem a respeito da Conferência Internacional sobre População e Desenvolvimento (Cairo 1994 e Cairo+20) ou dos Objetivos do Desenvolvimento Sustentável (ODS), que devem nortear a agenda internacional pós-2015, em especial no que diz respeito à erradicação da pobreza e à redução da desigualdade.

O autor também não discute o problema da "estagnação secular" (SOLOW, 2014) e muito menos a perspectiva do decrescimento econômico defendida pela escola da economia ecológica. Segundo Ortega (2014, p. 2): “Piketty gasta cerca de quatro páginas de sua obra para tratar dos limites do crescimento, mas não consegue resolver adequadamente o fato de que o crescimento ilimitado é insustentável em um planeta finito".

De maneira explícita, Piketty se abstém de prever o futuro do crescimento demoeconômico. Em vez disso, ele promete trabalhar com diferentes cenários para a dinâmica da distribuição da riqueza, pois considera difícil prever o ritmo das inovações tecnológicas e os níveis prospectivos da fecundidade. O autor chama a atenção para o processo de convergência da renda entre os "países desenvolvidos” e os "países em desenvolvimento" (com destaque para a China), mas considera que os fatores de divergência podem voltar a prevalecer à medida que não haja redução das desigualdades regionais de renda.

Embora considere que tanto o ritmo de incremento do PIB global quanto o da população mundial cairão no século XXI em relação ao século anterior, Piketty opta, na projeção média,

\footnotetext{
${ }^{1}$ Com exceção da Ásia em desenvolvimento, a economia mundial atual se caracteriza pela predominância das rendas de patrimônio em detrimento das rendas de atividade, o que explica a maior parte do desemprego na zona do euro e as tendências de baixo e instável crescimento econômico. A indústria regride sua participação no produto e os serviços avançam levando à queda dos ganhos de produtividade, fenômeno denominado por certos estudos como "atolamento da produtividade no terciário".
} 
por um cenário relativamente otimista de crescimento da renda percapita de cerca de 1,2\% ao ano nos países ricos no longo prazo, bem acima das previsões de Robert Gordon (consideradas pessimistas), e não aprofunda a discussão sobre os desequilíbrios e dificuldades que os países de rendas média e baixa devem encontrar nas próximas décadas. A América Latina, por exemplo, que conseguiu reduzir a pobreza e experimentou elevado crescimento econômico durante o boom do preço das commodities, já apresenta desempenho da renda per capita abaixo das economias avançadas em 2013-2015, segundo relatório do Fundo Monetário Internacional (IMF, 2014).

De certa forma, a opção de Piketty a favor do desenvolvimento não é gratuita, pois ele está confessamente mais interessado na análise do aumento da desigualdade e da concentração da riqueza, uma vez que, como economista keynesiano, não vê grandes problemas ambientais no crescimento econômico. Sem maiores preocupações com os limites do crescimento, ele dá ênfase ao conflito distributivo entre as classes sociais e às possibilidades de políticas públicas para mitigar os efeitos da má distribuição da renda e da riqueza.

Outro grande mérito do livro de Piketty, mas no âmbito epistemológico, é a contestação, com base nos dados empíricos coletados, de vários pressupostos, hipóteses ou enfoques axiomáticos da teoria econômica tradicional de base neoclássica e walrasiana. Entre estes, está a estabilidade das participações do trabalho e do capital no produto total, derivada do uso conveniente de funções de produção Cobb-Douglas, para justificar uma visão harmoniosa do conflito distributivo. Entretanto, o grau de desigualdade é resultado de processos históricodemográficos e não da convergência para uma configuração idealizada e mítica de um equilíbrio puramente econômico. A riqueza concentra-se quando a taxa média de retorno sobre o capital $(r)$ é maior do que a taxa de crescimento econômico ( $g$ ), isto é, $r>g$.

Ao comentar sobre Pareto, um dos ícones da ciência econômica estabelecida, Piketty argumenta que "o caso de Pareto é interessante pois ilustra uma certa ilusão da estabilidade eterna à qual conduz, por vezes, o uso imoderado da matemática em ciências sociais. (...) Em verdade, nada é mais falso: quando se estuda as desigualdades numa perspectiva histórica, o que é importante e o que deve ser explicado, não são as fugazes estabilidades, mas antes as grandes mudanças" (p. 367 e 368).

Destacam-se também a inversão, empiricamente constatada por Piketty, da curva de Kuznets e a datação histórica da teoria do ciclo de vida de Modigliani. As regularidades macroeconômicas entre poupança familiar, investimento e crescimento econômico envolvidas pela teoria do ciclo de vida refletem o contexto econômico-demográfico do pós-guerra (1945-1975), em que as rendas de atividade ainda suplantavam as rendas de patrimônio, pois $r<g$, graças às altas taxas de ocupação e de crescimento econômico veiculadas pelo regime de acumulação fordista nos países da OCDE. Não deve portanto, ser interpretada como uma “lei universal econômico-demográfica” completamente alheia às estruturas patrimoniais e às especificidades da acumulação de capital no capitalismo do século XXI.

Piketty, no entanto, não pretende posicionar-se em franca oposição teórica com a mainstream dos economistas, mas principalmente apontar os limites e lacunas interpretativas 
em face da evolução histórica. Isso certamente garantiu-lhe o direito de ser ouvido mesmo entre meios acadêmicos dominados pela ciência econômica ortodoxa, a explosão das vendas e a rápida difusão midiática.

O caso brasileiro - emblemático de alta concentração de renda e de patrimônio - constitui uma das lacunas do livro de Piketty, que, segundo o autor, deveu-se à indisponibilidade de dados compatíveis com os que obteve para os países selecionados em seu estudo. Pode-se então aproveitar esse espaço franqueado e apresentar algumas características distributivas da economia brasileira, a partir da segunda relação de Piketty, $\beta=\frac{K}{Y}=\frac{S}{g}$, onde a razão capital/renda é igual à taxa de poupança agregada $s$ dividida pela taxa de crescimento da renda total disponível, ou simplesmente taxa de crescimento econômico. Observe-se que essa estatística macroeconômica inclui também a poupança das empresas (contabilmente equivalente aos lucros retidos) e não somente a poupança das famílias (resultante dos lucros distribuídos e dos rendimentos salariais). Como $S=S . Y$, onde $S$ é a poupança total macroeconômica e $Y$ é a renda bruta disponível, a segunda relação de Piketty é equivalente a $S=K . g$ que, em termos dinâmicos, pode ser escrita como $\frac{d S}{d t}=\frac{d K}{d t}=\frac{d Y}{d t}$.

Essa equação expressa o crescimento da poupança $(d S / d t)$ como função da acumulação de riqueza $(d K / d t)$ e do crescimento da economia. Entretanto, a formulação não explicita a composição da poupança entre famílias e empresas, nem como se reparte entre suas duas principais formas de alocação - ativos financeiros ou ativos reais, notadamente, produtivos -, mas mostra que é possível a expansão da poupança pela acumulação das rendas de patrimônio, a despeito das tendências de baixo crescimento econômico que caracterizam o Brasil no século XXI. Porém, na economia brasileira atual, a formação de poupança na circulação bancária e financeira não implica aportes economicamente significativos de recursos para financiar o investimento produtivo. Ela implica a elevação das rendas de propriedade por meio da acumulação de patrimônio e tem como contrapartida as reduzidas taxas agregadas de poupança macroeconômica.

Para compreender como isso é possível, deve-se recorrer à diferenciação entre poupança improdutiva e poupança produtiva proposta por Aglietta (2001), um especialista em macroeconomia financeira. Os recursos poupados alocados nas transferências de propriedade de ativos já existentes não criam ativos novos e, por isso, compõem a poupança improdutiva. Já a poupança produtiva resulta da alocação dos recursos diretamente para a formação de capital fixo das empresas e, portanto, expande a capacidade produtiva instalada, o potencial de geração de emprego e renda, criando, assim, novos ativos.

O caso brasileiro pode ser analisado a partir dessa distinção fundamental, com base no conceito de financeirização (financialisation, já bastante difundido pela literatura econômica internacional), pois a "lei dinâmica" de Piketty em que $r>g$ há muito tempo tem sido constatada pelos estudos sobre os regimes de crescimento dominados pela acumulação rentista-patrimonial - os padrões do tipo finance-led growth regime (BOYER, 2000, por exemplo) e finance-dominated accumulation regime (STOCKHAMMER, 2004). Essas pesquisas 
ressaltam que os processos de financeirização das economias contemporâneas surgem da generalização, tanto no âmbito nacional quanto em mercados globais, das alternativas de revalorização financeira e rentista dos capitais, em ativos de alta rentabilidade e liquidez, comparativamente às imobilizações de recursos exigidas pelas atividades diretamente produtivas. Consequentemente, a baixa taxa de poupança agregada da economia brasileira resulta da intensa substituição de poupança produtiva por poupança improdutiva, graças à elevada renda financeira, particularmente de juros, que esse tipo de economia proporciona aos detentores de capital, bancos e rentistas.

O Brasil, com sua forte tradição patrimonialista e passado escravista, é um dos países mais desiguais do mundo. A novidade ocorrida no início do século XXI, mostrada pelos dados da Pesquisa Nacional por Amostra de Domicílios(PNAD), foi a queda da desigualdade, medida pelo rendimento médio mensal de todas as fontes, com o Índice de Gini passando de 0,570 em 2002 para 0,521 em 2009. Contudo, entre 2011 e 2013, o Índice de Gini variou somente de 0,506 para 0,501, mostrando muito mais uma estabilidade do que uma queda da distribuição pessoal da renda.

Outras metodologias mostram resultados preocupantes quando se consideram a concentração funcional da renda e a distribuição da riqueza. Artigo do pesquisador peruano Germán Alarco Tosoni (2014) mostra que a participação dos salários no PIB na América Latina sempre foi baixa e caiu entre 1950 e 2011. No Brasil, que reproduz o padrão latinoamericano, os valores mais altos, com participação dos salários em quase 50\% do PIB, foram registrados no governo Juscelino Kubitschek. A participação dos salários no produto total atingiu o nível mais baixo na virada do milênio e apresentou uma pequena recuperação na última década, a partir de 2004, mas sem alcançar o nível de 1957.

Estudo realizado por Medeiros et al. (2014), utilizando dados da PNAD e a renda declarada pelas pessoas ao Imposto de Renda, encontrou um índice de Gini de 0,696 em 2006, seguido por 0,698 em 2009 e 0,690 em 2012. A pequena variação também indica estabilidade e não queda na desigualdade brasileira. Porém, mesmo incluindo dados do Imposto de Renda, o estudo ainda não capta totalmente a renda dos muitos ricos, especialmente o rendimento das pessoas jurídicas e todo o processo de sonegação.

Artigo de Marcio Pochmann (2006) mostra que, no Brasil, somente 5 mil famílias, de um total de 51 milhões, absorviam 45\% de toda a renda e riqueza do país. O relatório sobre a riqueza global, do banco Credit Suisse (2014), mostra que a parcela dos 10\% dos brasileiros mais abastados detinha $69,4 \%$ da riqueza em 2000, variando ligeiramente para 68,8\% em 2007 e atingindo o máximo de 73,3\% em 2014. Ou seja, embora não haja dados sistemáticos para medir a distribuição funcional da riqueza e da propriedade no Brasil, os poucos estudos existentes, que avaliam a desigualdade de patrimônio, apontam para uma situação de concentração ainda maior do que aquela constatada pelos índices de Gini da distribuição pessoal da renda.

Sem dúvida, o livro Capital in the twenty-first century é uma referência fundamental para o estudo da concentração de renda e riqueza. Após exame cuidadoso das séries históricas 
relativas à desigualdade, Piketty conclui pela revalidação necessária das ações públicas ou dos papéis dos Estados nacionais. Como, por sua natureza e lógica interna, o mercado possui tanto forças convergentes (que podem favorecer a equidade e a redução das desigualdades) como divergentes (que a intensificam), a justiça distributiva, que implica acesso à renda e à riqueza, só pode ser viabilizada por meio de instituições adequadas que disciplinem mercados, impondo limites ao uso privado dos capitais que conflitem com os direitos sociais nas democracias atuais.

\section{Referências}

AGLIETTA, M. Macro économie financière. Paris: La Découverte, v. 1 e 2, 2001.

BOYER, R. Is a finance-led growth regime a viable alternative to Fordism? A preliminary analysis. Economy and Society, v. 29, n. 1, Feb. 2000.

BRUNO, M.; DIAWARA, H.; ARAÚJO, E.; REIS, A. C.; MELLO NETO, M. R. Finance-led growth regime no Brasil: estatuto teórico, evidências empíricas e consequências macroeconômicas. Revista de Economia Política, v. 31, n. 5 (125), Especial 2011.

CREDIT SUISSE. Global wealth report 2014. Zurich, Switzerland, Oct., 2014. Disponivel em: 〈https:// publications.credit-suisse.com/tasks/render/file/?fileID=60931FDE-A2D2-F568-B041B58C5EA591A4).

GORDON, R. J. Is U.S. economic growth over? Faltering innovation confronts the six headwinds. Cambridge, Massachusetts, Aug. 2012 (NBER working paper, n. 18315). Disponível em: 〈http://www. nber.org/papers/w18315>

IBGE - Instituto Brasileiro de Geografia e Estatística. A janela para olhar o Brasil. PNAD - Pesquisa Nacional por Amostra de Domicílios: Brasil e síntese de indicadores 2013. Rio de Janeiro: IBGE, 18/09/2014. Disponível em: «http://www.ibge.gov.br/home/presidencia/noticias/imprensa/ppts/ 00 000018883109232014310419410583.pdf〉.

IMF - International Monetary Fund. World Economic Outlook Reports. Washington: IMF, Oct. 2014.

MADDISON, A. Contours of the world economy 1-2030 AD: essays in macro-economic history. London: Oxford University Press, 2007.

MEDEIROS, M.; SOUZA, P. H. G. F.; CASTRO, F. A. A estabilidade da desigualdade de renda no Brasil, 2006 a 2012: estimativa com dados do imposto de renda e pesquisas domiciliares. Setembro, 2014 (SSRN working paper). Disponivel em: 〈http://ssrn.com/abstract=2493877〉.

ORTEGA, N. Telling Piketty the real reason why economies can't keep growing. Foreign Policy in Focus, Jun. 2014. Disponivel em: ‘http://www.resilience.org/stories/2014-06-23/telling-piketty-the-real-reasonwhy-economies-can-t-keep-growing>.

POCHMANN, M. O desafio da distribuição equânime da renda e riqueza no Brasil. Economia e Desenvolvimento, v. 5, n. 1, p. 89-105, 2006. Disponível em: 〈http://periodicos.ufpb.br/ojs/index. php/ economia/article/view/3846/3058>.

SOLOW, R. Secular stagnation, affluent economies stuck in neutral. Finance \& Development, v. 51, n. 3, Sep. 2014.

STOCKHAMMER, E. Financialization and the slowdown of accumulation. Cambridge Journal of Economics, n. 28, p. 719-741, 2004.

TOSONI, G. A. Participación salarial y crecimiento económico en América Latina, 1950-2011. Revista Cepal, n. 113, agosto, 2014. Disponivel em: 〈http://www.cepal.org/publicaciones/xml/5/53445/ RVE113Alarco.pdf>. 


\section{Sobre os autores}

JoséE Eustáquio Diniz Alves é doutor em Demografia pelo Cedeplar/UFMG, com pós-doutorado no Nepo/ Unicamp. Professor titular do Programa de Pós-graduação em População, Território e Estatísticas Públicas da Escola Nacional de Ciências Estatísticas - Ence, do Instituto Brasileiro de Geografia e Estatística - IBGE.

Miguel Antonio Pinho Bruno é doutor em Economia pela EHESS-Paris e pelo IE-UFRJ. Professor do Programa de Pós-graduação em População, Território e Estatísticas Públicas da Escola Nacional de Ciências Estatísticas - Ence, do Instituto Brasileiro de Geografia e Estatística - IBGE.

\section{Endereço para correspondência}

Escola Nacional de Ciências Estatísticas

Rua Andre Cavalcanti, 106, sala 502, Bairro de Fátima

20231-050 - Rio de Janeiro-RJ, Brasil

Recebido para publicação em 21/10/2014

Aceito para publicação em 18/11/2014 